\title{
Implantation Site
}

National Cancer Institute

\section{Source}

National Cancer Institute. Implantation Site. NCI Thesaurus. Code C77678.

The anatomic site at which a material such as a tissue, graft, device or radioactive material is inserted with some intended degree of permanence. This term may also refer to the site of the uterus at which the early embryo is attached. 